\title{
Síndrome febril prolongado y alteraciones hepáticas
}

\author{
$\mathrm{M}^{\mathrm{a}}$ Carolina Marí Silva ${ }^{\mathrm{a}}$, José María Alonso Gordo ${ }^{\mathrm{b}}$ \\ Alejandro González Praetorius ${ }^{c}$, María del Carmen Sánchez González ${ }^{a}$
}

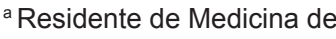
Familia y Comunitaria,

Centro de Salud

Guadalajara Sur, Guadalajara.

${ }^{\mathrm{b}}$ Médico de Família,

Centro de Salud

Guadalajara Sur, Guadalajara.

${ }^{c}$ Microbiólogo, Sección de Serología, Hospital Universitario de Guadalajara.

Correspondencia:

Carolina Marí Silva,

Centro de Salud

Guadalajara-Sur,

C/ Ferial $n^{\circ} 31,1^{\text {a }}$ Pta.,

Guadalajara, España.

Telf.: 949226508, e-mail:

carolina_mari@hotmail.com.

Recibido el 9 de marzo de 2011.

Aceptado para su publicación el 10 de abril de 2011.

\begin{abstract}
RESUMEN
La infección por citomegalovirus (CMV) debe ser investigada en pacientes sanos con cuadro pseudogripal consistente en fiebre, astenia, aumento inexplicado de los niveles de transaminasas y linfomonocitosis periférica. Es un cuadro relativamente frecuente, por lo que puede pasar totalmente desapercibido o con escasas manifestaciones clínicas, sobre todo en el paciente inmunocompetente. Los síntomas faríngeos y adenomegalias son menos frecuentes que en la infección mononucleósica por virus de Epstein-Barr.

Presentamos el caso de un paciente sin factores de riesgo que presenta un cuadro febril prolongado y alteraciones hepáticas, con evolución espontánea a la normalización y serología compatible con infección por CMV.
\end{abstract}

Palabras clave. Citomegalovirus, Hepatitis, Inmunocompetencia.

\section{ABSTRACT}

Persistent fever and liver alterations

Cytomegalovirus (CMV) infection should be investigated in healthy patients who have flu-like symptoms consisting of fever, fatigue, unexplained increase of transaminases and peripheral lymphomonocytosis. These are relatively common symptoms so they may pass completely unnoticed or with few clinical manifestations, especially in immunocompetent patients. Pharyngeal symptoms and swollen lymph nodes are less frequent than in mononucleosis infection caused by Epstein-Barr virus.

We report a case of a patient with no risk factors who presented with persistent fever and liver alterations, which resolved spontaneously and with serological findings compatible with a recent CMV infection.

Key words. Cytomegalovirus, Hepatitis, Immunocompetence.

\section{INTRODUCCIÓN}

La infección por citomegalovirus es un hecho relativamente frecuente y puede pasar desapercibida o con escasas manifestaciones clínicas, sobre todo en el paciente inmunocompetente. Los síntomas más habituales son, entre otros, fiebre, astenia, cefalea y mialgias, pudiendo acompañarse de moderadas alteraciones enzimáticas hepáticas y síndrome mononucleósico en sangre periférica (linfomonocitosis con linfocitos atípicos) ${ }^{1}$. El diagnóstico diferencial debe realizarse con la mononucleosis infecciosa por virus de Epstein-Barr (infección que aparece en pacientes muy jóvenes, con síntomas faríngeos más intensos y adenopatías cervicales más frecuentes $)^{1,2}$ y también con otras hepatitis agudas, si bien las alteraciones enzimáticas suelen ser más elevadas en éstas. La confirmación diagnóstica se efectúa mediante la determinación de anticuerpos específicos contra el CMV. Presentamos el caso de un paciente joven inmunocompetente que presenta un cuadro febril prolongado y alteraciones enzimáticas hepáticas moderadas, con remisión espontánea, y serología compatible con infección por CMV.

\section{OBSERVACIONES CLÍNICAS}

Paciente varón de 31 años de edad, trabajador informático, que consultó por cuadro febril de más de $38^{\circ} \mathrm{C}$ de 6 días de duración, faringodinia, tos leve 
y quebrantamiento general. No refirió antecedentes profesionales ni personales de riesgo, no había realizado viajes recientes ni presentaba hábitos tóxicos. Tres años antes había presentado un cuadro neumónico con buena evolución. La exploración física inicial no mostró signos de focalidad. La auscultación pulmonar y la faringe estaban dentro de la normalidad. Con la sospecha de cuadro viral se indicó tratamiento sintomático y observación.

Cuatro días después persistía fiebre ves-pertina, cefalea y astenia. La explora-ción física seguía siendo normal y a la palpación presentaba una pequeña adenopatía axilar; no presentaba lesiones cutáneas, no se apreciaban alteraciones en fondo de ojo y no se detectaban visceromegalias. Se realizó radiografía de tórax, sistemático de orina y urocultivo, sin hallazgos específicos. En la analítica se detectaron alteraciones enzimáticas hepáticas y monocitosis relativa; se realizó prueba de Mantoux y ecografía abdominal con resultados dentro de la normalidad. Una nueva analítica con serologías víricas, y frotis de sangre periférica, confirmó síndrome mononucleósico. El paciente continuó con fiebre, por lo que acudió al servicio de urgencias hospitalario, sin nuevos hallazgos, permaneciendo con tratamiento sintomático y reposo relativo.

La evolución analítica aparece en las tablas 1 y 2. A los 30 días aproximadamente del inicio del cuadro el paciente comenzó a encontrarse afebril, desapareciendo la astenia. La exploración continuó normal y se normalizaron las alteraciones enzimáticas hepáticas.

\section{COMENTARIOS}

El citomegalovirus, herpes virus de la misma familia que el virus de Epstein-Barr y que, como él, produce células características aumentadas de tamaño, es responsable del 10 al $20 \%$ de los síndromes mononucleósicos ${ }^{1}$. La infección suele contraerse por vía oral, requiriendo una exposición prolongada, por contacto sexual o por transfusión de hemoderivados ${ }^{1}$. Las manifestaciones clínicas más graves de enfermedad por CMV suelen producirse en recién nacidos, pacientes inmunodeprimidos, receptores de trasplantes y transfusiones y a veces en pacientes sanos; en estos casos puede dar lugar a enfermedad gastrointestinal, hematológica, afectación del sistema nervioso, retinitis o meningoencefalitis, neumonías, o afectación difusa grave y diseminada ${ }^{2,4}$. En los recién nacidos, por transmisión materna o perinatal, puede producir cuadros de exantema, adenopatías, hepatitis, microcefalia, retraso mental, coriorretinitis o alteraciones sensoriales o psicomotoras posteriores ${ }^{4}$.

Aunque las formas graves o sintomáticas son muy escasas, la infección por CMV es muy frecuente y se estima una prevalencia entre el 40 y el $80 \%{ }^{3,4}$. En los adultos sólo el $10 \%$ de los casos infectados suele dar manifestaciones clínicas ${ }^{1}$, siendo las más frecuentes ${ }^{3}$ las que se recogen en la tabla 3. La fiebre en los pacientes con CMV está presente en un $98 \%$ de los casos; es prolongada, con una duración media de 18 días, y un $25 \%$ de los casos supera las 3 semanas de duración, a diferencia de la mononucleosis por VEB, donde la fiebre tiene una duración de 1-2 semanas².

Otra de las manifestaciones más habituales en al adulto sano suele ser un síndrome mononucleósico con alteraciones hepáticas y anticuerpos heterófilos negativos, que tras una incubación de 20 a 60 días puede durar de 4 a 6 semanas $^{1,5}$. En los cuadros con complicaciones la afectación más frecuente suele ser la del tracto digestivo, sistema nervioso, hematológico, pulmón y ocular ${ }^{4}$.

Las alteraciones hepáticas, presentes en más del $90 \%$ de los casos, ocurren entre 7 y 14 días después del inicio de la fiebre ${ }^{2}$. La afectación suele consistir en moderados aumentos de las cifras de transaminasas (hasta 4 - 6 veces el valor normal en un $10-15 \%$ de los casos) y de fosfatasa alcalina, con escasa o nula elevación de la bilirrubina ${ }^{1,2}$, aunque a veces se pueden producir casos graves y con complicaciones ${ }^{6}$. El sustrato anatomopatológico es una necrosis leve de los hepatocitos con predominio de células mononucleares, la formación de granulomas con afectación portal y periportal y a veces colestasis ${ }^{1,2}$.

La manera más sensible de identificar el virus es mediante la amplificación de DNA por reacción en cadena de polimerasa (PCR). El diagnóstico serológico suele realizarse por determinación positiva de IgM específica (indicadora de infección reciente o activa) o por conversión serológica (aumento en cuatro veces de los títulos de $\lg )^{1,3}$, más específica pero más tardía. La IgM no suele estar presente hasta una semana después del inicio de los síntomas de la enfermedad, y puede permanecer positiva hasta un año después de la infección inicial ${ }^{1,3}$. También se ha desarrollado un test de avidez, para diferenciar infección reciente (baja avidez) de infección antigua (alta avidez) ${ }^{3}$. Menos habitual, y normalmente innecesario, es 
el aislamiento de virus en sangre, orina, exudado faríngeo o muestras de biopsia².

La evolución suele ser hacia la resolución espontánea, permaneciendo los títulos de anticuerpos elevados, y pudiendo dar lugar a cuadros intermitentes de reactivación, espontánea o en periodos de inmunocompromiso ${ }^{3}$. No suele requerirse tratamiento, y únicamente se indicarían antivirales en los casos de pacientesinmunodeprimidos, trasplantados y/o con manifestaciones clínicas graves, aunque los resultados no son concluyentes ${ }^{4}$.

En nuestro caso la fiebre sin focalidad, de duración intermedia, y el estado general conservado, en ausencia de riesgos, nos permitieron mantener una actitud conservadora y una estrategia diagnóstica y terapéutica posible y razonable en Atención Primaria. Ante la persistencia del cuadro febril se inició un primer estudio que detectó las alteraciones enzimáticas hepáticasyelsíndromemononucleósico con prueba de Paul Bunnell negativa. Una adecuada coordinación con el Servicio de Microbiología permitió la realización de las pruebas iniciales de sospecha de CMV y su posterior confirmación, a la vez que el cuadro clínico permanecía estable y posteriormente entraba en resolución.

\begin{tabular}{l|ccc}
\hline & Día $\mathbf{1 0}$ & Día $\mathbf{1 5}$ & Día 30 \\
\hline ASAT & $96 \mathrm{U} / \mathrm{l}$ & $354 \mathrm{U} / \mathrm{l}$ & $40 \mathrm{U} / \mathrm{l}$ \\
ALAT & $239 \mathrm{U} / \mathrm{l}$ & $609 \mathrm{U} / \mathrm{l}$ & $100 \mathrm{U} / \mathrm{l}$ \\
GGT & $47 \mathrm{U} / \mathrm{l}$ & $68 \mathrm{U} / \mathrm{l}$ & $46 \mathrm{U} / \mathrm{l}$ \\
FA & $81 \mathrm{U} / \mathrm{l}$ & $100 \mathrm{U} / \mathrm{l}$ & $72 \mathrm{U} / \mathrm{l}$ \\
PCR & $44,9 \mathrm{mg} / \mathrm{l}$ & - & $6,7 \mathrm{mg} / \mathrm{l}$ \\
Bilirrubina total & $1 \mathrm{mg} / \mathrm{dl}$ & $1 \mathrm{mg} / \mathrm{dl}$ & $0,8 \mathrm{mg} / \mathrm{dl}$ \\
Leucocitos & $6,98 \times 1000 / \mu l$ & $9,90 \times 1000 / \mu l$ & $7,20 \times 1000 / \mu l$ \\
Neutrófilos & $47,8 \%$ & $31,6 \%$ & $29,4 \%$ \\
Linfocitos & $35,8 \%$ & $58,3 \%$ & $60,2 \%$ \\
Monocitos & $13,9 \%$ & $7,4 \%$ & $8,8 \%$ \\
\hline
\end{tabular}

Tabla 1. Evolución analítica.

\begin{tabular}{l|cc}
\hline & Día 15 & Día 30 \\
\hline CMV (PCR) & Positivo indeterminado & - \\
CMV IgM (Elisa indirecto) & - & 1,03 (Positivo) \\
CMV IgM (Elisa) & - & Positivo \\
Avidez IgG CMV (Elisa) & - & Baja \\
Epstein-Barr & Negativo & Negativo \\
\hline
\end{tabular}

Tabla 2. Evolución de las serologías.

\begin{tabular}{l|c}
\hline Síntomas & Porcentaje \\
\hline Fiebre & 98 \\
Mialgia & 61 \\
Astenia & 55 \\
Faringitis & 38 \\
Cefalea & 34 \\
Exantema & 31 \\
Esplenomegalia & 38 \\
Adenomegalias & 28 \\
Hepatomegalia & 25 \\
Linfocitosis & 72 \\
Linfocitos atípicos & 88 \\
Elevación Transaminasas & 91 \\
Elevación F. Alcalina & 39 \\
Elevación bilirrubina & 15 \\
\hline
\end{tabular}

Tabla 3. Síntomas y signos más habituales en pacientes con síndrome mononucleósico por $\mathrm{CMV}^{2}$. 


\section{BIBLIOGRAFÍA}

1. Vujacich C, Vidiella G, Barcelona L, Sturba E, Stamboulian D. Infección por citomegalovirus con compromiso hepático en adultos inmunocompetentes. Medicina (Buenos Aires). 2006; 66:206-10.

2. Cohen JI, Corey GR. Cytomegalovirus infection in the normal host. Medicine (Baltimore). 1985; 64(2):100-14.

3. Gutierrez Salinas J, Cruz Tovar L. Estudio de la seroprevalencia de la infección por citomegalovirus a través de la concentración sérica de IgG en un hospital de tercer nivel. Rev Mex Patol Clin. 2008; 55(4):175-86.
4. Rafailidis PI, Mourtzoukou EG, Varbobotis IC, Falagas ME. Severe cytomegalovirus infection in apparently immunocompetent patients: a systematic review. Virology Journal. 2008; 5:47.

5. Rodriguez Fernández JM, Meije Castillo Y. Varón de 27 años con fiebre de 3 semanas de evolución y malestar general. Medicine. 2010; 10(58):4019.

6. Izquierdo Rubio S, Taxonera Samsó C, Ladero Quesada JM, Almansa Menchero C, Díaz Rubio M. Infeccion diseminada y severa por citomegalovirus en paciente inmunocompetente. An Med Interna (Madrid). 2002; 19(5):234-6. 